\title{
Retraction: Li, M., et al. W-GPCR Routing Method for Vehicular Ad Hoc Networks. Sensors 2020, 20, 3406
}

\author{
Min Li ${ }^{1}$, Zhiru Gu ${ }^{1}{ }^{*}$, Yonghong Long ${ }^{1}$, Xiaohua Shu ${ }^{1}$, Qing Rong ${ }^{1}$, Ziji Ma ${ }^{2}$ and Xun Shao ${ }^{3} \mathbb{D}$ \\ 1 College of Traffic Engineering, Hunan University of Technology, Zhuzhou 412007, China; \\ minli0103@126.com (M.L.); lyhcai@126.com (Y.L.); sxhdata@126.com (X.S.); Rong08017@163.com (Q.R.) \\ 2 College of Electrical and Information Engineering, Hunan University, Changsha 410082, China; \\ zijima@hnu.edu.cn \\ 3 Division of Information and Communication Engineering, Kitami Institute of Technology, \\ Hokkaido 090-8507, Japan; x-shao@ieee.org \\ * Correspondence: guzhiru@126.com
}

check for

updates

Citation: Li, M.; Gu, Z.; Long, Y.; Shu, X.; Rong, Q.; Ma, Z.; Shao, X. Retraction: Li, M., et al. W-GPCR Routing Method for Vehicular Ad Hoc Networks. Sensors 2020, 20, 3406 Sensors 2021, 21, 1998. https:// doi.org/10.3390/s21061998

Received: 2 March 2021

Accepted: 10 March 2021

Published: 12 March 2021

Publisher's Note: MDPI stays neutral with regard to jurisdictional claims in published maps and institutional affiliations.

Copyright: (C) 2021 by the authors. Licensee MDPI, Basel, Switzerland. This article is an open access article distributed under the terms and conditions of the Creative Commons Attribution (CC BY) license (https:// creativecommons.org/licenses/by/ $4.0 /)$.
The journal retracts the article [1], cited above, published in the journal, Sensors. The authors contacted the publisher regarding the robustness of the results. The selection of weight parameters was not sufficiently rigorous, resulting in doubts concerning the scientific validity of the theoretical models and simulation results.

Adhering to our procedures, an investigation was conducted by the Editor-in-Chief with the editorial office of Sensors. The extent of the error is significant and, therefore, in accordance with the journal's procedural requirements, this article is retracted.

The authors agreed to this retraction and apologize for any inconvenience caused.

\section{Reference}

1. Li, M.; Gu, Z.; Long, Y.; Shu, X.; Rong, Q.; Ma, Z.; Shao, X. W-GPCR Routing Method for Vehicular Ad Hoc Networks. Sensors 2020, 20, 3406. [CrossRef] [PubMed] 